\title{
Location-Aware App to Support Heritage Trail Experience in Singapore
}

\author{
Jude Yew, Google, Inc., San Francisco \\ Sameer Deshpande*, Griffith Business School, Griffith University, Brisbane \\ Natalie Precians, Communications, Australian Catholic University, Sydney \\ Kelvin Cheng, Rakuten Institute of Technology, Rakuten Inc., Tokyo \\ Ellen Do, CUTE Center, National University of Singapore and ATLAS Institute, University of \\ Colorado, Boulder \\ * corresponding author
}

Keywords: City, Heritage, management, Technology, Singapore

\section{Acknowledgments}

We acknowledge Dr. Yong Ming Kow for his work on an early version of the app called CrowdTrails and Dr. Ayman Shamma for his help with developing the user study. Additionally, we thank Joy Ng, Krishna Kannan, Dung Nguyen, Fajilatun Nahar, Daniel Chua, Barry Chew, Tay Rui Wen, Michelle Tan, and Justin Eng who served as developers and research assistants.

This research is supported by the National Research Foundation, Prime Minister's Office, Singapore under its International Research Centres in Singapore Funding Initiative and the National Heritage Board, Singapore. 


\title{
Location-Aware App to Support Heritage Trail Experience in Singapore
}

\begin{abstract}
We present insights from the design and development process of Singapore Heritage Trails (SGTrails), a location-aware mobile application that supports users' exploration of sites of heritage and cultural value. Our findings are based on (a) a survey to understand users' perceptions about the role of technology, (b) a field study to compare a prototype version with a paper guide, and (c) analysis of implementation, initial adoption, and usage to uncover the multilayered meanings of heritage locations. Drawing on Activity Theory, we examine the ecology of actors and tools necessary to facilitate the co-curating and experiencing of sites of cultural heritage.
\end{abstract}

\section{Introduction}

Mobile technologies and location-aware services are fundamentally changing the ways in which we engage with and experience places and locations (Giaccardi, 2012). In particular, 'locative media,' which refer to mobile media technologies such as Global Positioning Systems (GPS), link space-time and other information to places (San Cornelio \& Ardèvol, 2011). One of the key opportunities that locative media provides is the ability to traverse between the screen and physical spaces, creating hybrid and mediated experiences of place. These technologies are increasingly being implemented across heritage and cultural sites, like museums and monuments (van Dijk, Lingnau, \& Kockelkorn, 2012), with varying degrees of success (Ciolfi, 2013). Technology, in particular, location-aware mobile applications, are playing an increasingly important role in shaping the visitor's experience of cultural and historical sites and locations. But what do visitors expect from technology at heritage sites and locations? And how does technology influence their experience while at these places? This paper details our insights gained in developing Singapore Heritage Trails (SGTrails)- through partnerships with 
stakeholders and using an ecological activity-centered approach that addresses different facets of a heritage location.

To answer these questions, we present a multi-part study:

- An exploratory survey with 159 respondents that examined how technologies can mediate visitors' perceptions and experiences of heritage sites;

- A field study conducted with 20 participants comparing a paper guide and a prototype of the SGTrails app. Specifically, how each intervention impacted the participants' experience of a heritage trail; and,

- An analysis of the development process and how people adopted and used the SGTrails app - an application that was developed in collaboration with the National Heritage Board (NHB) of Singapore.

Figure 1 illustrates the development and research process that we undertook for this study. Overall, the results of our studies and experience with the development process highlights the need to better account for the multiple layers of meaning found in heritage sites and the ecology of actors and tools that cocurate the trail experiences at a heritage location. We then draw on Activity Theory (Kaptelinin \& Nardi, 2006) to frame the insights gained from this project, and to guide the design and implementation of future location-aware applications that mediate visitors' experience of heritage sites and locations.

FIGURE 1 ABOUT HERE 


\section{Background}

\section{Trails as a way to experience heritage}

Derived from Timothy and Boyd's discussion of the 'route,' we understand the 'trail' to be the 'designation of a circuit or course that links similar natural or cultural features together into a thematic linear corridor' (2014, p.4). More broadly, trails are 'linear, human-designated attractions' (ibid, p.5). Extending this understanding, we include space-place theory and draw on Tuan's (1977) conception that meaning-making helps visitors transform a space into a place. One way in which meaning is created out of space is through the creation of narratives via walking trails. Such narratives evoke a sense of self and place (Leon, 2009) through the movement-pause dynamic of a heritage trail. We adopt this model to investigate the efficacy of the trail as a mechanism for experiencing heritage.

Among heritage enthusiasts, trails are widely shared as artefacts conveying the multifaceted characteristics of a variety of environments such as museums, historical districts, and neighborhoods (Kow et al., 2014). For this study, we recognize the 'trail' as more than just a series of 'pauses' (spots). Rather, the trail incorporates a wider landscape and includes the space in-between spots in addition to the spots themselves to comprise a comprehensive and narrative means of accessing and understanding heritage. Nevertheless, the trail goer is not bound to the trail as a single means of experiencing heritage sites.

Hayes and MacLeod (2007) analyzed 75 heritage trail brochures to identify design principles for heritage trails. The principles in brochures that evoked 'fulfilling' and 'meaningful' perceptions about trails provided opportunities for enrolment (symbolized through participation in a trail), engagement (quizzes, photo opportunities, treasure hunts, and mementos), and personalization (cater trails to suit different groups). Increasingly, technology is playing a significant role in engaging and personalizing heritage trail experiences. Traditionally, trails have sought to provide a 'narrative' in the delivery of 
information about the various facets of a heritage location (Timothy \& Boyd, 2015). However, using narratives as a method of conveying the experience of a place is currently seen as too passive to engage the trail goer. Giaccardi and Palen (2008) suggest that ICT might be the means to develop the relationship between present day citizens and heritage and further engage trail goers at heritage sites. We establish this relationship in our study that focuses on the use of technology in mediating the trail goer's experience of a heritage location.

An important aspect of our study related to creation of trails that local and international tourists would share with peers. For this purpose, we drew upon Barber's (2019) typology about creation of trails sourced from government, market, and the community. Our study considered these differences when understanding user experience and how these experiences influence trail development and exploration. We also draw upon learnings from Miles' (2017) organic development and Fagence's (2017) purposive development of trail to understand how it enhances experience of heritage and subsequently the trail itself. Additionally, as Cantillon (2019) argues in the Gold Coast (Australia) context, trails are a useful way for tourists to navigate and appreciate rapidly changing urban landscapes, an aspect of close interest in the current Singaporean context.

\section{Technology-mediated experience of cultural heritage}

The digitalization of cultural heritage transforms the way in which we experience heritage (Giaccardi, 2012). If we understand heritage sites to consist of many layers of meanings (for example, physical, infrastructural, and socio-cultural layers, to name a few), then adding a 'digital layer' enables the visitor to traverse between the screen and the physical topography of a site. The implementation of locative media provides space-time and other information to heritage places (San Cornelio \& Ardèvol, 2011). For instance, with reference to the museum, Ghiani et al. (2009) find that location-aware technologies 
enabled the diverse clientele of museums to personalize their experiences through the provision of additional information during their visit. In this sense, digital technologies are more flexible and interactive in meeting the needs of users when compared with traditional, paper-based modes of information sharing.

Brown and Chalmers (2003) note that tourists, despite being highly organized, are deliberately unstructured in order to capitalize on unexpected opportunities. Their observation leads them to identify the specific need for augmented GPS and informational technology. Indeed, researchers are moving beyond singular implementation of mediated place experiences and have started to develop frameworks and guidelines for designing location-aware technology that supports the creation of self-exploratory learning guides in neighborhoods, cities, and museums (Cranshaw et al., 2014).

For many location-based apps, maps appear as a default interface choice. Maps are often not, however, the optimal presentation paradigm (Church et al., 2010) and instead should be utilized to support alternative interfaces and representations of information. Thus, one of the goals of this project was to investigate better representations of information and user interfaces around heritage and cultural sites. We began this investigation by carrying out an exploratory survey. Prior to conducting all participant research studies presented in this manuscript, we obtained human subjects' approval from the ethics review committee of the National University of Singapore.

\section{Exploratory Survey}

We interacted with potential mobile-trail-app users to understand perceptions and modes of engaging with heritage. Respondents were recruited in three ways: (a) email invitation sent to Singaporean heritage enthusiasts, (b) a call posted on Facebook pages of groups relevant to Singapore Heritage, and (c) a request made by a research company to Singapore-based respondents. These respondents were 
recruited because few would have experienced heritage sites in Singapore via a heritage trail focused mobile app at that time. In general, the traditional mode of engagement with these heritage sites takes place through paper guides/brochures or physical markers and signboards present at the sites themselves. Our survey attracted one hundred and fifty-nine respondents, who reported how they engaged with heritage sites and institutions, what they understood of heritage, and what they expected from the use of technology to mediate heritage site experiences. Questions asked about what tools and aids visitors used when visiting a heritage site; how visitors felt encouraged to better engage with these sites; and how a mobile application could be designed to enhance their involvement. Some questions required the selection of a response to a 7-point Likert scale (1 being 'strongly disagree' and 7 being 'strongly agree') while others were open ended. The average respondent age was 36.5 years (SD = 11). Seventysix of the 159 participants were female (48\%), although 14 respondents did not provide this information. The majority of respondents $(66 \%)$ were Singaporeans of Chinese descent. Fifty-seven respondents worked in the service industry, 37 respondents worked in managerial or professional roles, and 15 were students.

\section{Survey Findings}

\section{Attitude towards Singapore's heritage sites}

One hundred and forty-four (90\%) survey respondents indicated that they visit a heritage site at least once a year. This is significant given Singapore has only 13 official trails at various heritage sites administered by the National Heritage Board (NHB). Additionally, the awareness of and engagement with heritage was highly important, with most respondents indicating that they either 'agree' or 'strongly agree' with the statements 'I am interested in Singapore's heritage.' $(\mathrm{M}=5.71, \mathrm{SD}=1.33)$. 
This is a significant finding in a country where urban planning decisions have been driven by practical considerations, such as land-use efficiency, rather than by connection to place.

Of the eight possible options (see Figure 2), respondents selected an average of 4.8 different keywords for heritage, revealing the multiple layers of understanding of heritage. These results reflect an understanding that heritage, like the notion of place (Ciolfi, 2011), is not reducible to a single, synoptic meaning but is instead the result of continual human interactions in the lived world (Byrne, 2008).

\section{FIGURE 2 ABOUT HERE}

\section{Tools and aids currently used}

The survey participants were also asked about the tools and aids they currently use to help them explore Singapore's heritage sites. As shown in Figure 3, the top two tools utilized were Google maps and paper guides and brochures of the heritage sites. Whilst Google maps is user-friendly and assists with navigation of a site, one of the respondents reported a drawback of using this tool: 'You're too busy following the blue dot on the map to get to your location, so you're not exactly appreciating the experience of walking to the place of interest unless you make a conscious effort to do so' (P15). Respondents also identified both drawbacks and advantages of using the paper guide. P11 highlighted that, '[the] information is good but limited because it's print. You won't get less, or more.' While P76 noted that '[with the paper brochure] I can multitask.'

Mobile applications were relatively under-utilized (19\%), which might be attributed to a lack of awareness and difficulty accessing them: the mobile app often required users to be prompted to download and install the app from either Apple's App Store or Android's Play Store. 


\section{FIGURE 3 ABOUT HERE}

In response to the statement, 'the tool increased my engagement', respondents found all tools to be useful [(paper guide $\mathrm{M}=5.42, \mathrm{SD}=1.27, \mathrm{~N}=71),($ mobile app $\mathrm{M}=5.57, \mathrm{SD}=1.31, \mathrm{~N}=30$ ), and (Google maps $\mathrm{M}=5.90, \mathrm{SD}=1.22, \mathrm{~N}=40)$ ]. To get a sense of digital tools utilized, data were combined for those who used either a mobile app or Google maps or both, resulting in engagement of $\mathrm{M}$ $=5.83, \mathrm{SD}=1.16, \mathrm{~N}=60$. When paper guide perceptions were compared with the digital tools, the latter were found to be marginally more engaging (mean difference $=0.35, \mathrm{t}=1.85, \mathrm{df}=45, \mathrm{p}<.10$ ); similarly when paper guide was compared with those who used both paper guide and digital tools, the amalgamation of digital and information-based tools marginally increased user-engagement (mean difference $=0.17, \mathrm{t}=1.85, \mathrm{df}=45, \mathrm{p}<.10$ ). Respondents utilized multiple tools at a heritage site, with only 17 respondents indicating that they rely on a sole tool. This highlights a need to facilitate the experience of heritage sites as one that is mediated and complemented by a variety of tools that allow for choice and preference.

When asked to indicate the features they considered necessary for a mobile application to support the heritage location experience, respondents selected features relating to location services and physical guidance (GPS, mapping, locating nearby sites, etc.) more frequently than features relating to sociality ('like' a site, share photos to Facebook, forming groups, etc.) (See Figure 4). 'Directions to sites' was the most frequently selected feature $(n=109)$ followed by the feature to suggest sites based on current location $(n=107)$, as well as to recommend sites of interest while on a trail $(n=83)$.

FIGURE 4 ABOUT HERE 
Using Pearson's Chi-Square test, we found that users who reported using paper brochures to guide them around heritage sites also thought that features for navigation, such as notification when nearing a site, were important inclusions in an app for heritage exploration $\left(\chi^{2}=6.63, p<0.05\right)$. Likewise, respondents who had used physical markers to guide an exploration of a heritage site were more likely to consider features for sociality and navigation as necessary to an app for the exploration of heritage sites. These features included an ability to 'create your own trail' $\left(\chi^{2}=5.01, \mathrm{p}<0.05\right)$, share site to Facebook $\left(\chi^{2}=\right.$ $13.19, \mathrm{p}<0.01)$, share photos $\left(\chi^{2}=4.45, \mathrm{p}<0.05\right)$, have an audio guide $\left(\chi^{2}=4.75, \mathrm{p}<0.05\right)$, and a notification when near a site $\left(\chi^{2}=5.94, \mathrm{p}<0.05\right)$. This relationship reveals a particular user archetype amongst our respondents that, while frequently adopting paper-based or physical tools for heritage exploration, sees the value and use in integrating features for navigation and sociality into an app for heritage sites. From this we conclude that non-digital (paper-based) guides are unable to perform the functions that users perceive they would most benefit from in their exploration.

In response to our query on how an application could contribute to their experience at heritage sites, respondents suggested that an application could 'play the role of a tour guide', helping them to 'find the way' and 'plan a route'. These responses highlight our respondents' view that technologies can help visitors navigate and augment the experience of being at heritage sites. As Tuan (1977, p.136) highlights, '[s]pace is transformed into place as it acquires definition and meaning.' We postulate that such guidance and augmentation help visitors transform a space into a place by helping them make meaning of their visit to heritage sites. Also significant amongst the responses was the feeling that such a mobile application would provide users with greater flexibility and independence and remove the need to have to purchase or obtain a paper guide. This perceived need for navigation to support the heritage 
experience posed a challenge for us to design an app that moves away from a map-based interface (Church et al., 2010) yet retains the capacity to navigate.

The findings generated by this survey provided us with specific design directions to pursue and implement. Next, we describe how we addressed the survey findings to develop a prototype mobile application and compared it with NHB's paper guide.

\section{Mobile Application Prototype}

Our purpose in developing a prototype app was to test the efficacy of mobile app features in promoting engagement with heritage. Designed for the Android platform, the prototype contained a single trail, drawn from the existing pool of official NHB trails. The user interface comprised of marked points of interest (POIs) or 'spots' in an area of historic interest in Singapore, which mirror the spots marked on the official paper guide for NHB trails. The spots were marked along an inferred trail and marked with letters ' $A$ ' through ' $L$ ' to distinguish them from each other at a glance (see Figure 5). The trail screen and individual spot screens included relevant information also adapted from the existing NHB paper guide. Notably, the prototype app contained geo-locative features for navigation around the trail site, the tool most frequently cited as necessary by our survey respondents.

FIGURE 5 ABOUT HERE

The app also supported sociality, with features such as 'Visited' for 'checking of' spots as the trail goer progressed along the trail, and 'Shoutout,' which allowed the user to leave a comment about the trail they were on. Our survey results also highlighted an interest in knowing about the experience of others visiting a heritage site. To support this, users could document their experience of place by leaving 
comments and reading comments left by previous visitors to the site via the mobile application.

Comments could be left in text or image form, with users having the option of uploading photos. The inclusion of these features for sociality in this combination were intended to address the social layer of heritage sites, whilst simultaneously facilitating engagement with cultural and historical layers as the app guides the user through the physical space (Ciolfi, 2013). By facilitating visitors to socially interact, we sought to help visitors gain from each other's experiences of heritage sites and perhaps share and collaboratively develop meaning from the heritage site that they had just visited (Tuan, 1977).

\section{User Study}

To test the effectiveness of our prototype, we compared visitors' experiences of heritage locations via our prototype mobile application with a paper trail guide. The goal of this study was to examine whether the visitor's experience of place can be mediated through a mobile application and whether this mediation produces superior experience to paper guides.

Twenty participants were recruited via posters disseminated at high-traffic spots around a university campus, shopping malls, websites, and social media platforms. Participants needed to be familiar with using a smartphone. The mean age was 25.8 years $(\mathrm{SD}=6.9)$. Fourteen participants were undergraduate students and the rest were working adults. Six participants were tourists and the rest were Singaporeans.

The participants were instructed to explore a less touristy neighborhood, the Balestier district, in Singapore. The Balestier area reflects Singapore's historical significance as a British trading post and its transformation to a modern city-state. Balestier presents an interesting palimpsest of religious and cultural uses, lending it well to an examination of how using technology can influence the experience of heritage sites. Additionally, it is located away from the tourist centers of the city and participants would be less familiar with the locations conveyed on this heritage trail. 
Participants were equipped with either the prototype app $(n=15$; Figure 5$)$ or the paper guide from which the content of the app (trail spots and information) was derived ( $\mathrm{n}=5$; visit this website for a copy of the paper guide: https://www.nhb.gov.sg/ /media/nhb/files/places/trails/balestier/balestier.pdf). Participants were randomly assigned to the app or paper guide condition. Distribution of the paper guide and app were done on-site, with installation of the app completed by participants on their phone before embarking on the trail. After a brief introductory session, participants walked alone along the Balestier Heritage trail. They were encouraged to explore the heritage site at a comfortable pace. The longest exploration took 6 hours and the shortest was 35 minutes. Upon completion, a one-hour semi-structured interview was conducted with each participant. Interviews focused on user experience of the trail, spots, sociality features, and experience of place. Whilst the interviewer guided the discussion, participants were encouraged to talk about their personal experiences of walking the heritage trail.

\section{User Study Findings}

We discuss how the mobile app addressed the layers of meaning in a heritage site and facilitated the serendipitous exploration of place. We then highlight advantages and shortcomings of our mobile app in relation to the paper guide.

\section{Guidance versus Serendipitous Exploration}

Participants viewed the navigational aspect of the app positively, stating that it 'can help get my sense of direction' (Participant C3), and 'get back to the spots that I missed' (Participant B1). Nevertheless, some viewed it as overly prescriptive. For example, participant C3 reported: 'I don't like structure. It will be more tiring to dictate [that] I need to go A, B, C, D. You don't have to dictate the road but show the path from $K$ to L, showing the shortest path... So not dictating but be[ing] helpful.' This excerpt demonstrates a desire to be guided by the app, and that the app might be useful in its capacity to 
highlight the 'shortest path' at times. However, the app's suggestions for the sequence in which sites should be visited by labelling spots became 'tiresome' for the user, as he or she felt constrained by this directive. An overly prescriptive trail reduced the sense of enjoyment and increased the feeling that the trail was conducting rather than guiding the experience of place. This finding was, however, not consistent across all participants, with D2 stating that 'a highlighted path will help you to focus' revealing that the trail served a purpose in forging a sense of direction and overall meaning. Indeed, nine of our participants indicated they would like a highlighted trail in order to manage time effectively. Participant D2 noted, 'if you don't have time... say you only have half an hour, [and you want to see] the must-see spots during the half an hour.'

In accepting that visitors have different goals and that not all users seek to lose themselves in a place, we came to understand that the trail enables a methodical and efficient exploration of place for some. Whilst for others, the overly prescriptive feature with the sequence of POIs may reduce the experience of a heritage site; these participants would perhaps benefit from greater flexibility to explore and discover new things off the trail.

We thus observed a tension between the app's role as a GPS tool and the opportunity for unbounded exploration. Indeed, there is an attraction in 'getting lost,' as was pointed out by participant C1: 'Getting lost does have an interesting, unexpected element. It's not entirely bad to get lost.' But users also want to be 'found' again. Participant A1 commented that 'getting lost is okay but [I] just want to make sure I can reach the next place.' It seems that while geo-locative technology plays a role in orienting and directing the user, trail goers harbor an inherent desire for balance between guidance and serendipitous, self-guided exploration. Or, as participant A4 indicated, 'Yes to guided paths, but not that guided.'

Indeed, the paradoxical experience of 'losing oneself' in a place without ever really being lost is one that mobile apps might seek to facilitate. In its ability to provide up-to-date information on the go and to 
adapt to the movements of the user and provide appropriate and accurate locative data and directives, the mobile app can perform the role of tour guide, stepping in to intervene when the experience of getting lost transcends from serendipity into inconvenience. The ability to provide up-to-date information in 'real time' prevents these sites from being viewed as static and interminable in the eyes of the visitor. This suggested to us that the app should allow visitors to update the information about each heritage site along a trail and thus co-curate the trail information.

\section{Experience of Place}

In conceiving of heritage sites as multi-layered, the features of the prototype app were developed to address this complex notion of place. The inclusion of features for sociality, for example, was intended to speak to the social layer of heritage engagement. During the user study, however, the use of the 'Visited' and 'Shoutout' buttons eluded expectations. On being asked to reflect upon the use of these functions, users revealed that while they were keen to record the spots they had visited and at which they had a memorable experience, they were less inclined to do so at spots they found uninteresting or underwhelming. At these spots, these functions were used out of a sense of obligation and often retrospectively to fulfil a perceived sense of duty in having visited a spot. For example, participant D2 noted that '[in places that] are more memorable [I'll click] immediately... Others, I will remember about the check-in only after I left. So, I click for the sake of clicking. But those memorable ones are the ones I want to check-in; the rest is clearing the task.' Thus the 'journaling' aspect informs quality and level of engagement with heritage sites.

These findings suggest that sociality must be designed carefully if it is to increase engagement. This is due in part to the individuality of experience of place. Our user study reveals that place and its experience is a personal phenomenon. Participant A5 remarked that 'the feelings that I've got- excited; curious - [are] not just feelings. ' He/she had difficulty articulating what more they were, jumping 
between 'knowledge' and the interpretation of text and reflection as an interplay with feelings. Participant C3 echoed the individuality of experience, stating that 'experience of place is my personal relation to all the happenings... in my trip. From pre-trip, where I research [about the site], to onsite experience of what happened to me, and what I discovered.'

The user study further corroborates our survey findings that learning about the experiences of others is valued by trail goers. For example, participant B2 told us that '...this personal type of narrative is interesting... you can compare your experience with the [previous visitor's] experience.' Although, by contrast, when asked to reflect upon how the sociality feature 'Shoutout' impacted the interaction with the trail sites, participant B2 replied that '... at the beginning I was trying to post a Shoutout and go back to the trail.... While I was doing that, I wasn't paying attention to where I was walking. So, it didn't enhance my interaction with physical space.' This response reveals a relative lack of interest in features to support sociality for a mobile app. Compared with features for navigation and site recommendation, the perceived need for sociality was relatively limited among the survey respondents. Conversely, social features like the 'Shoutout' may not have met the needs of users; on the contrary, it may have detracted from the experience of place.

\section{Paper versus Mobile App}

Our user study also revealed that both paper guide and mobile apps comprise benefits and drawbacks in their capacity to mediate the visitor experience to heritage sites. Regarding the information available via the mobile app, five participants of the mobile app condition noted that they would read the information on the go. Participant C3 noted that 'I read on the go... as I walk from one spot to another.' Ito, Okabe \& Anderson (2009) describe this form of behavior with mobile devices as 'Cocooning' - where users engaged with mobile content often isolate themselves from the physical environment and others in that location. Visitors equipped with the paper guide, on the other hand, required more time to absorb 
information. Some participants 'didn't read the paper guide at all' (Participant D5) as they needed time to sit down and absorb the information. This highlights a significant distinction between the way in which paper guides and mobile apps are used by heritage site visitors. Participant A5 reflected similarly: I'm used to walking and typing SMS on the go... [however], for the paper map, the information is much more valuable, but needs more time to digest.' This is a particularly interesting comment as the information on the app and paper guide were identical. It sheds light on the tension between the need for immediate gratification via the easily consumable information (available on-the-go via the app) and perceived 'valuable' information.

The tension between 'valuable' and on-the-go information presented a design challenge for our project that we attempted to resolve while developing such an app.

\section{Singapore Heritage Trails Mobile Application}

Drawing on the findings of the survey and user study and in collaboration with the National Heritage Board in Singapore, we developed a mobile app to support experience at heritage sites, Singapore Heritage Trails (SGTrails) ${ }^{1}$. At the time of development, Singapore's National Heritage Board curated 13 pre-determined heritage trails, including the Kampong Glam Heritage Trail series, the World War 2 Trail, and the Balastier Heritage Trail. Most often guided via a paper brochure, these trails were largely static and, as such, their narratives consistent yet inflexible and unable to adapt to the diverse needs of trail goers. On the ground, trails and spots were sometimes sign-posted, allowing trail goers to marry paper map to topography. A small number of trails were also available via location-aware applications. Their use, however, required that an individual application be downloaded for each trail. Further, the

\footnotetext{
${ }^{1}$ https://crowdtrails.org/sgtrails.html
} 
applications did not allow for personalization or interaction, acting only as a 'soft' copy of the original paper trail maps. SGTrails brought together all 13 trails curated by the National Heritage Board, as well as others developed by official enterprises such as Singapore Tourism Board, National Parks Board, the Maritime and Port Authority of Singapore, and the Urban Redevelopment Authority. Development of SGTrails manifested a cooperative approach to the co-curation of heritage trails in Singapore. The goal was for SGTrails to be a 'Wikipedia'-like platform of cultural/heritage trails in Singapore. It was envisioned that official heritage trail information would exist side-by-side with other trails contributed by users, and community and interest groups. It was expected that authorities, organizations, and individuals would use the app to curate and share trails with peer users.

\section{Features}

Participants in the user study had reported that an overly prescriptive trail reduced the sense of enjoyment and increased the feeling that the trail was conducting rather than guiding the experience of place. In SGTrails, spots were therefore made indistinct from each other and could be visited in any order/sequence, creating a greater sense of overall identity for the trail. This introduced a sense of serendipitous exploration into the trail experience. Whilst these unmarked spots helped delineate the trail, a line denoting the trail path was introduced to create a sense of coherence and to maintain a sense of direction for the overall trail. Also, from the interviews, it became clear that a highlighted path can create a sense of purpose and direction, as well as bring into focus the issue of time and scale.

The app also allowed users to search for nearby sites, to sort trails according to categories such as food, architecture, towns, war, and community, and to record their experiences. In response to the need to support 'journaling', 'commenting' and the 'option to upload photos' enabled users to document their experiences (see Figure 6). 


\section{Adoption and usage analysis}

The beta-version of SGTrails was launched in June 2015. Analysis conducted before the final-version launch revealed a total of 1,627 downloads (from iOS App Store and Android Google Play). We recorded 354 account creations, $21.8 \%$ of downloads. The rest (1,273 users) simply browsed, without creating an account, or did not use the app at all after downloading. Overall, we observed 9,698 sessions of use with an average session time of 10 minutes and 54 seconds. In terms of features, we recorded 191 likes and 40 comments. Comments reveal unique insight into the experiences of users ('[I] used to live in Toa Payoh... we used to frequent the market at Lorong every weekend. [I] still remember the friendly chicken stall uncle who always gave us a discount') and indicate sites in which users see particular value ('Perhaps this can be Singapore's next UNESCO site [referring to Singapore's Civic District]? It retains many old and important colonial buildings after all'). Users also contributed 45 trails (including 18 incomplete trails for testing, seven food trails, and two by student classes). Interestingly, all these trails remained private with their curators choosing not to share them with other users of the app, further debunking our assumption that social interaction and sharing enhances the experience of visiting heritage sites.

The final version was released in May 2016 and contained 99 heritage trails available for browsing by users who downloaded the app. Of these, 69 trails were curated by government agencies (e.g., National Heritage Board, Singapore Tourism Board, National Parks Board, Sites and Monuments), 22 by secondary and primary schools, six by community groups, and one by an individual. Altogether, there 
were a total of 1,001 spots. As of September 2018, SGTrails had been downloaded by 19,700 users from the iOS App Store and 5,980 from Android Google Play.

Post-official launch, an in-app survey was conducted to assess the extent to which the SGTrails app helped its users engage with Singapore's heritage. The survey was timed to pop-up within two minutes of active use. Users were recruited to the survey via Facebook posts and from a pool of local university students. A total of 150 responses were completed. Respondents reported high levels of overall satisfaction with the SGTrails app. When asked to rate the app on a scale of one to five, $97 \%$ of respondents attributed three or more stars in response to the question 'How would you rate your overall satisfaction with this app?'. With regard to the usability of the app, users found the system easy to negotiate and agreed that it assisted with their engagement (in terms of learning something new) with heritage sites. Some users also suggested improvements to enhance their experience of using the app, including an indication of the 'estimated time needed to complete each trail,' an audio guide, and alternate language selection.

\section{An Activity Systems Approach to Understanding the Heritage Experience}

A key takeaway from our study is to embrace an ecological perspective when supporting and enhancing the visitor's experience at heritage sites. While developing the SGTrails app, we knew we couldn't do it alone, so we partnered with many actors; in return we received diverse benefits: users gave us useful feedback, local community groups contributed trail information, and governmental bodies such as the NHB provided necessary partnership and bestowed official legitimacy. Our partnership with NHB gave us access to the 13 heritage trails curated by NHB and to the heritage trails content created by other governmental agencies. The ecological perspective also helped us to understand the complex relationship between the visitor, the technological and non-technological tools, and the heritage location. 
This led us to develop the app that possesses navigational features (e.g., GPS wayfinding, maps) and provides the serendipitous opportunities and light guidance that allows users to engage with the locals and to immerse in the environment.

Given the diverse stakeholders and input that contributed to the development of the SGTrails app, how can we make sense of the role that technology plays in mediating heritage trail experiences? One way to better consider the complex interactions between the various actors, tools, and contexts involved in creating the heritage experience for the visitor, is to use Activity Theory (Kaptelinin \& Nardi, 2006). Activity Theory puts forward the notion that human experience does not take place in isolation; instead it acknowledges human behavior to be complex, socially situated, and technologically mediated. Activity Theory is useful because it presents a structure for thinking about the use of technology and the social norms that emerge within the context of an 'activity system'. As conceptualized by Engeström (1999), an activity system is made up of: the subject (individuals/groups that act and whose agency is analyzed), an object (that which is acted upon), and the artefacts (tools, community rules, and divisions of labor) that mediate the relationship between the subject and the object (see Figure 7). The dynamic ecologies of components within an activity system are highly interconnected and interdependent. As such, human activities are seen as complex socially situated phenomena that are both dependent on and have influence over the employed tools and artifacts (Engeström, 1999). Relevant to this view is the notion of the 'socio-technical systems' (Hutchins, 1995; Ackerman, 2000) where any characterization of technology (e.g., online communities) must capture interaction and interdependencies between the social and technical components of the system. The notion of socio-technical systems is complementary to Engeström's conception of an activity system as composed of a complex ecology of interacting and interdependent components. 
Figure 7 (Engeström, 2001) conceptualizes the experience of heritage locations as an activity system from the perspective of the visitor. In this figure, we find that the overarching goals/motives (2) of the visitor to a heritage site/location (1) are to engage and experience heritage sites meaningfully. The heritage experience is mediated for the visitor by an ecology of tools (3) such as the SGTrails app as well as by the other non-technological aids such as paper guides or physical markers at the locations. These tools deliver guidance and historical information, that is maintained and contributed by the larger community (5) surrounding the heritage sites and involves the local community, institutions, and other visitors who contribute and share information about their heritage experiences. Additionally, the visitor's experience of a heritage site is also determined by the rules (4) and social norms about how interaction and engagement at each heritage site occurs. There are several layers of experience in a heritage site and each one has its own rules and norms for how the visitors engage with that layer. For instance, in the social layer, our studies have highlighted that visitors to heritage sites share and post their experiences of a heritage site only when the place is meaningful and significant to their visit. Lastly, it takes a village of individuals to deliver the heritage site experience for the visitor. There is an informal division of labor (6) between individuals such as guides and shopkeepers, local heritage communities, and official institutions such as the NHB.

Utilizing an activity systems lens provides a clear representation of the various actors, the participants (app end-users), the community (such as heritage communities and official organizations), and the ecology of tools/guides involved in the mediation of heritage experiences. An awareness of these 
components is key to the development of technologies if they are to adequately negotiate pressure points and meet the diverse needs of the actors.

Our project brings to light the existence of challenges, such as those resulting from data and technological limitations, as well as policy conflicts and opposing agendas, which ought to be addressed. Conversely, we identify several strengths, such as the potential for collaborative efforts in the dissemination of heritage materials and their conservation. Our collaboration, for instance, awarded us access to resources (content and publicity) and expedited the development of such systems.

Activity Theory also served as a valuable lens to view the findings of our three studies that depicted a dynamic and diverse conceptualization of heritage, as experienced by the visitors at heritage sites. It is therefore essential to map the ecology of relations of various actors and tools that contribute to visitors' heritage experience in order to design dynamic and flexible technologies. By viewing the visitor's heritage experience as an activity system, we were able to conceive of digital technology as multilayered and as part of, not distinct from, the place-experience ecology. Indeed, our findings suggest that the mediated experience is enhanced when the end user is understood as an actor in dialogue with other elements of a system.

\section{Managerial Implications}

So, what do our insights from embarking on a journey to develop an app to support visitor experience imply for tourism marketers? Visitors are no longer the 'passive observers' (Scarles \& Lester, 2013) they once were. Increasingly, visitors to locations of interest, such as heritage sites, are looking to play a role in mediating their own experience of place (Osborne, 2000). The development and refinement of tools to support this experience is therefore a priority. Like in other spheres of life, tourists experiencing heritage sites expect technological aids such as mobile applications and other digital platforms to play a 
bigger role in improving their engagement and satisfaction. Government and private tourism companies have embraced some of these changes (Liang et al. 2017); however, application of mobile apps dedicated to experiencing heritage trails lags.

Our study urges a need to develop new tourism-support opportunities, like other contexts (Lee, Tussyadiah, \& Zach, 2010). Mobile apps facilitate better navigation and digital socializing, which enhance user engagement and increase attractiveness of exploration of trails. By providing such digital platforms, tourism marketers can also enhance their own social media footprint. Based on our learnings from the design of the app, process of partnership, and interactions with stakeholders, we recommend tourism marketers provide digital opportunities that reflect a user-centered design process. This includes embracing continuous research reflecting genuine audience-orientation that closely supports the nature of tourists' desire to explore heritage sites (Choi, Wang, \& Sparks, 2018; Nguyen \& Cheung, 2016) and provides multilayered heritage experience in which the user and other stakeholders are actively involved in co-curating the digital content. 


\section{References}

Ackerman, M. (2000). The intellectual challenge of CSCW: The gap between social requirements and technical feasibility. Human-Computer Interaction, 15(2), 179-203.

Barber, L. B. (2019). Heritage tours and trails on foot in Hong Kong: towards a typology that crosses the tourist-local divide. Journal of Heritage Tourism, 14(4), 295-307, DOI:

\subsection{0/1743873X.2018.1510937}

Brown, B. \& Chalmers, M. (2003). Tourism and mobile technology. In K. Kuutti \& E. H. Karsten (Eds.), Proceedings of the Eighth European Conference on Computer Supported Cooperative Work, Helsinki, Finland: Kluwer Academic Press.

Byrne, D. (2008). Heritage as social action. In G. Fairclough, R. Harrison, J. Schonfield, \& J. H. Jameson (Eds.), The Heritage Reader (pp. 149-173). London: Routledge.

Cantillon, Z. (2019). Urban heritage walks in a rapidly changing city: Tensions between preservation and development on the Gold Coast, Australia. Journal of Heritage Tourism, DOI:

\subsection{0/1743873X.2019.1618315}

Choi, K., Wang, Y., \& Sparks, B. (2018). Travel app users' continued use intentions: It's a matter of value and trust. Journal of Travel \& Tourism Marketing, DOI: 10.1080/10548408.2018.1505580.

Church, K., Neumann, J., Cherubini, M., \& Oliver. N. (2010). The ‘Map Trap'? An evaluation of map versus text-based interfaces for location-based mobile search services. World Wide Web 2010, 261270.

Ciolfi, L. (2011). Augmented places: Exploring human experience of technology at the boundary between physical and digital worlds. In K. James-Chakraborty \& S. Strümper-Krobb (Eds.), Crossing Borders: Space Beyond Disciplines (pp. 205-222). NY: Peter Lang. 
Ciolfi, L. (2013). The collaborative work of heritage: Open challenges for CSCW. In O. W. Bertelsen, L. Ciolfi, M. A. Grasso \& G. A. Papadopoulos (Eds.), Proceedings of ECSCW 2013 (pp. 83-101). London: Springer.

Cranshaw, J., Luther, K., Gage, P., \& Norman, K. (2014). Curated City: Capturing Individual City Guides Through Social Curation. CHI, 2014: Proceedings of the Conference on Human Factors in Computing Systems, (pp. 3249-3258).

Engeström, Y. (1999). Activity theory and individual and social transformation. In Y. Engestrom, R. Miettinen, \& R-L. Punamaki (Eds.), Perspectives on Activity Theory (pp. 19-38). Cambridge: Cambridge University.

Engeström, Y. (2001). Expansive learning at work: Toward an Activity Theoretical Reconceptualization. Journal of Education and Work, 14(1), 133-156.

Fagence, M. (2017). A heritage 'trailscape': Tracking the exploits of historical figures - an Australian case study. Journal of Heritage Tourism, 12(5), 452-462.

Giaccardi, E. \& Palen, L. (2008). The social production of heritage through cross-media interaction: Making place for place-making. International Journal of Heritage Studies, 14(3), 281-97.

Giaccardi, E. (Ed.) (2012). Heritage and Social Media: Understanding heritage in a participatory culture. London: Routledge.

Ghiani, G., Paterno, F., Santoro, C., \& Spano, L.D. (2009). UbiCicero: A location-aware, multi-device museum guide. Interacting with Computers, 21, 288-303.

Hayes, D. \& MacLeod, N. (2007). Packaging places: Designing heritage trails using an experience economy perspective to maximize visitor engagement. Journal of Vacation Marketing, (13)1, 45-58.

Hutchins, E. (1995). Cognition in the Wild. Cambridge, MA: MIT Press. 
Ito, M., Okabe, D., \& Anderson, K. (2009). Portable objects in three global cities: The personalization of urban places. In R. Ling \& S. Campbell (Eds.), The Mobile Communication Research Annual Volume 1: The Reconstruction of Space \& Time through Mobile Communication Practices (pp. 67-88). New Brunswick, NJ: Transaction Publishers.

Kaptelinin, V. \& Nardi, B. (2006). Acting with Technology: Activity Theory and Interaction Design. Cambridge: MIT Press

Kow, Y. M., Nie, J., Martinez, X. R., \& Cheng, K. (2014). Trails as boundary objects of a heritage community. 3rd South East Asian Network of Ergonomics Societies International Conference 2014, Singapore.

Lee, G., Tussyadiah, I. P., \& Zach, F. (2010). A visitor-focused assessment of new product launch: The case of Quilt Gardens Tour in Northern Indiana's Amish country. Journal of Travel \& Tourism Marketing, 27(7), 723-735, DOI: 10.1080/10548408.2010.519677.

Leon, C. (2009). Movement and Belonging: Lines, Places, and Spaces of Travel. New York: Peter Lang. Liang, S., Schuckert, M., Law, R., \& Masiero, L. (2017). The relevance of mobile tourism and information technology: An analysis of recent trends and future research directions. Journal of Travel \& Tourism Marketing, 34(6), 732-748, DOI: 10.1080/10548408.2016.1218403.

Miles, S. (2017). Remembrance trails of the great war on the Western front: Routes of heritage and memory. Journal of Heritage Tourism, 12(5), 441-451, DOI: 10.1080/1743873X.2016.1242589

Nguyen, T. H. H. \& Cheung, C. (2016). Toward an understanding of tourists' authentic heritage experiences: Evidence from Hong Kong. Journal of Travel \& Tourism Marketing, 33(7), 999-1010, DOI: $10.1080 / 10548408.2015 .1075460$.

Osborne, P. (2000). Travelling light. Photography, Travel and Visual Culture. Manchester: Manchester University. 
San Cornelio, G.S. \& Ardévol, E. (2011). Practices of place-making through locative media artworks. Communications, 36(3), 313-333.

Scarles, C. \& Lester, J-A. (Eds.) (2013). Mediating the tourist experience: From brochures to virtual encounters Current Developments in the Geographies of Leisure and Tourism (pp. 1-11). Brookfield, VT: Ashgate.

Timothy, D. J. \& Boyd, S. W. (2014). Tourism and Trails: Cultural, Ecological and Management Issues. Bristol: Channel View.

Tuan, Y-F. (1977). Space and Place: The Perspective of Experience. University of Minnesota Press.

van Dijk, E. M. A. G., Lingnau, A., \& Kockelkorn, H. (2012). Measuring enjoyment of an interactive museum experience. Proceedings of the 14th ACM international conference on Multimodal interaction - ICMI 2012, 14, 249-256. 
Location-Aware App

Figure 1. Mobile app development process

Exploratory Audience Survey on

the Role of technology at Heritage

Sites

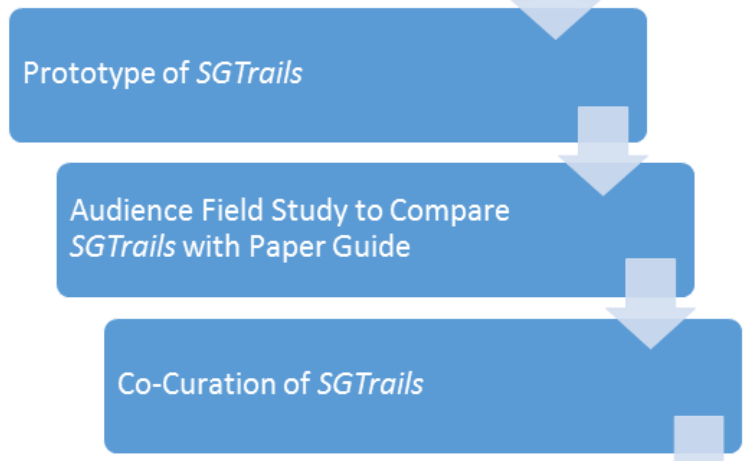

Enhanced Visitor Experience of

Heritage via Trail 
Location-Aware App

Figure 2. Survey participants' multiple meanings of heritage

What does heritage mean to you?

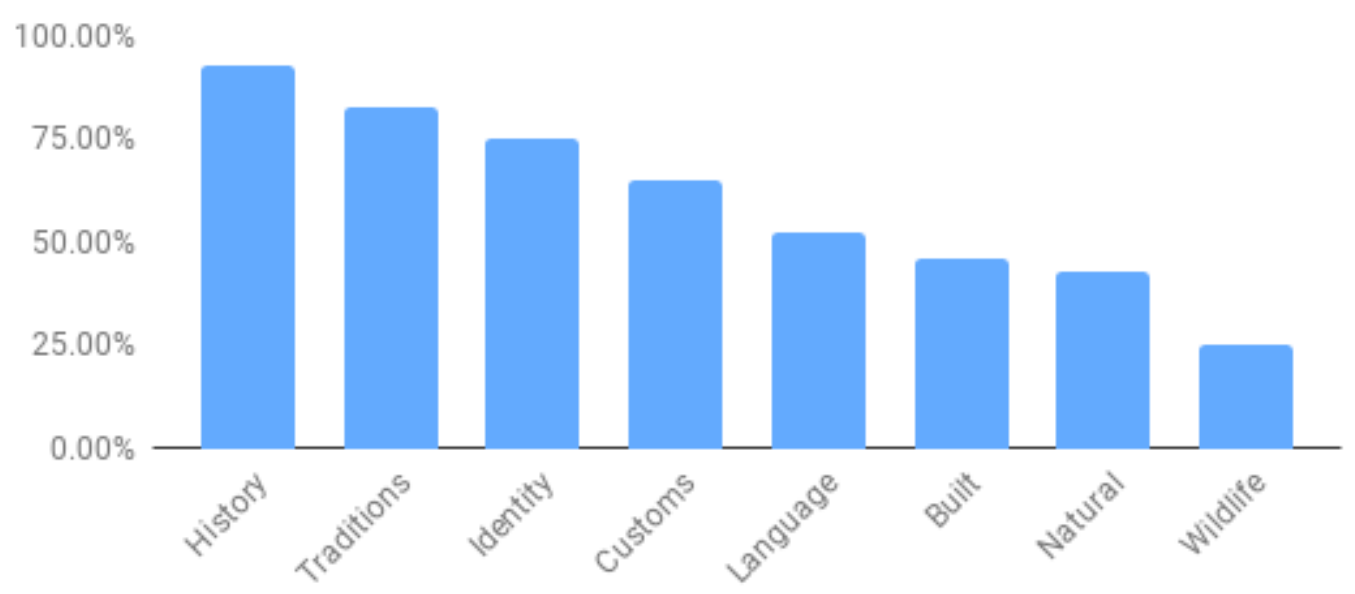


Location-Aware App

Figure 3: Current tools and aids used to explore Singapore's Heritage

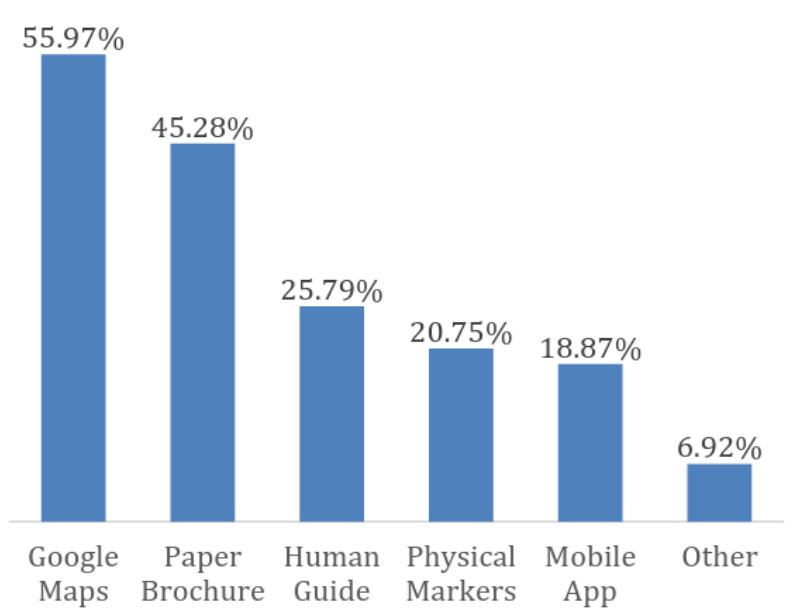


Location-Aware App

Figure 4: Desired features for engaging with Heritage sites

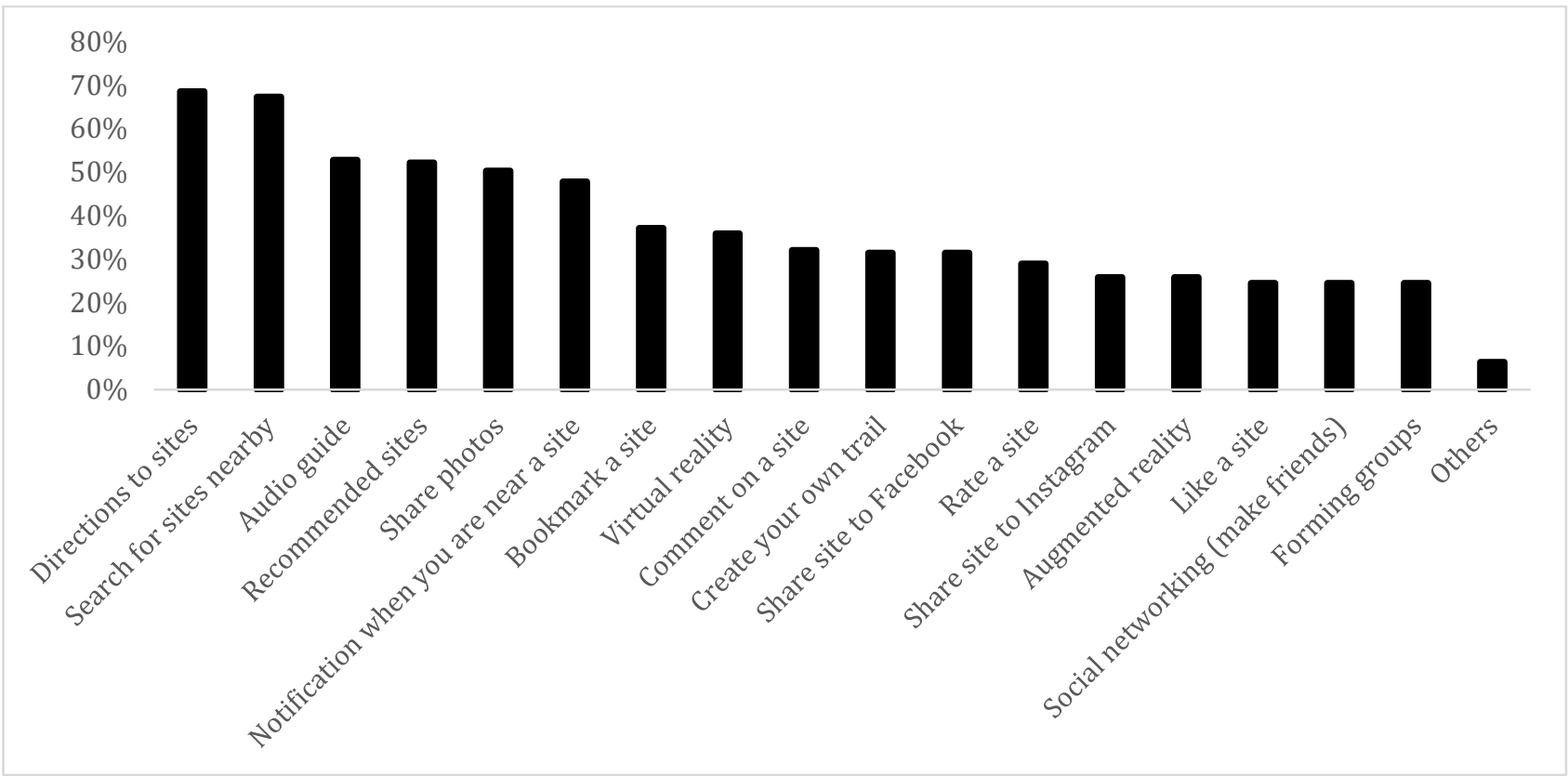


Figure 5. Prototype app featuring the Join button (left), Visited button (center), and Shoutout (right).

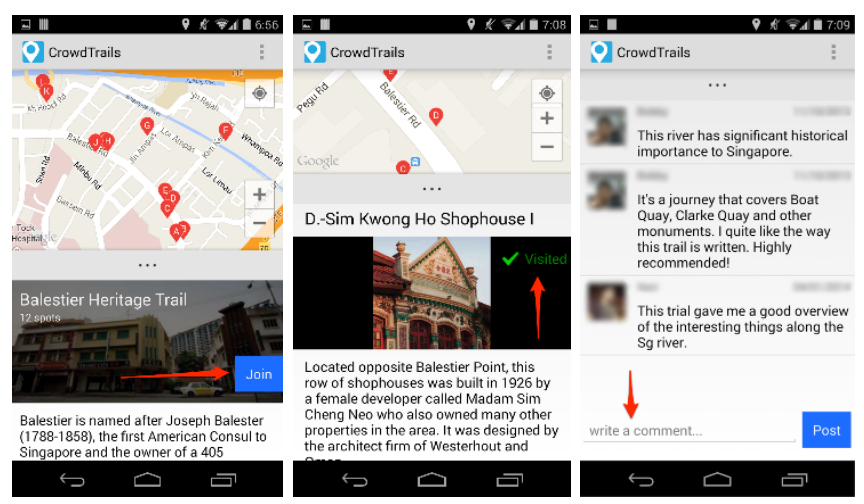


Figure 6. Screenshots from the SGTrails app (clockwise from top left) (a) trail information (b) map showing a trail with multiple indistinct spots (c) search (d) users sharing their own experiences.
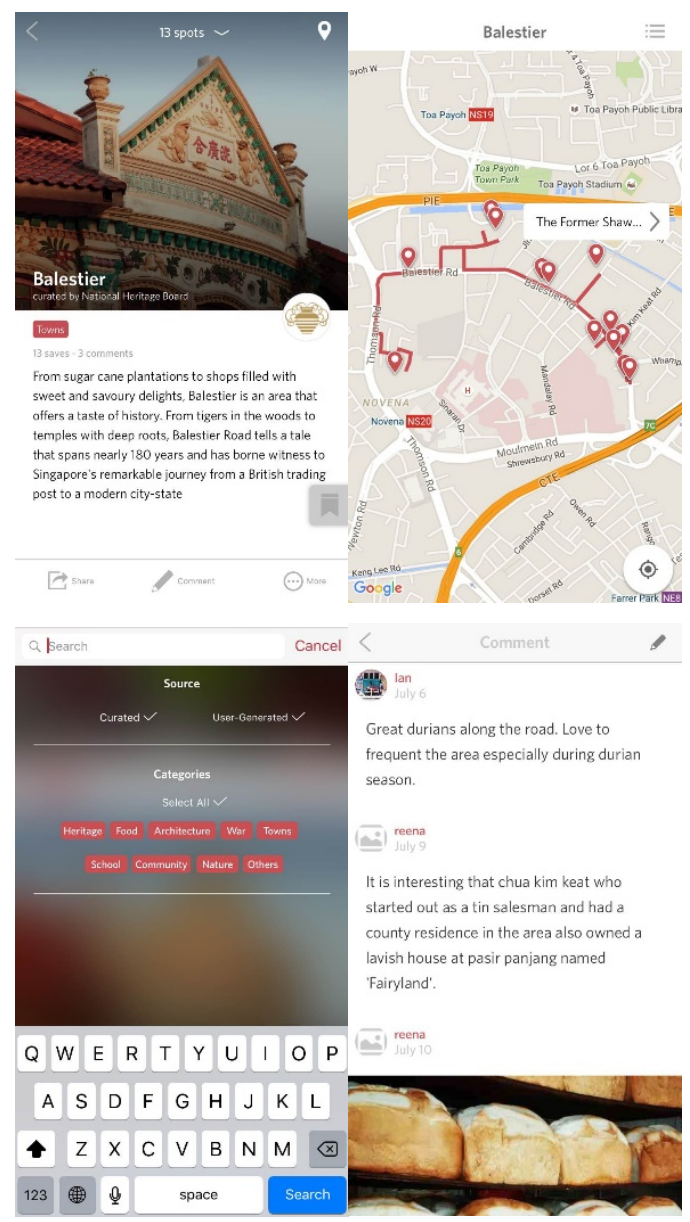
Figure 7. Experiencing heritage as an activity system from a visitor's perspective

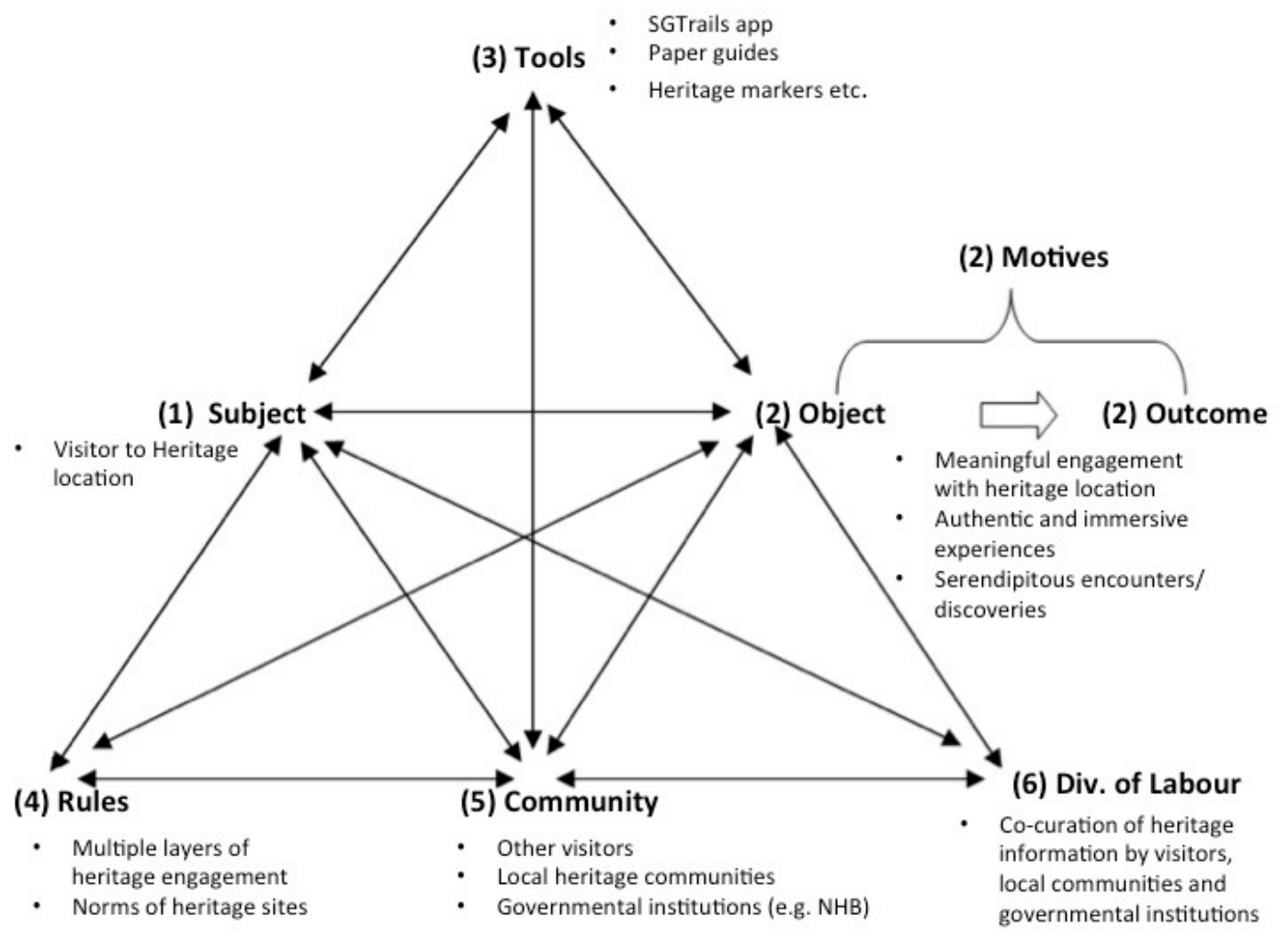




\section{Figure Caption List}

Figure 1. Mobile app development process

Figure 2. Survey participants' multiple meanings of Heritage

Figure 3: Current tools/aids use to explore Singapore's Heritage

Figure 4: Desired features for engaging with Heritage sites

Figure 5. Prototype app featuring the Join button (left), Visited button (center), and Shoutout (right).

Figure 6. Screenshots from the SGTrails app (clockwise from top left) (a) trail information (b) map showing a trail with multiple indistinct spots (c) search (d) users sharing their own experiences.

Figure 7. Experiencing heritage as an activity system from a visitor's perspective 